\title{
Effects of plantar fascia on first metatarsophalangeal joint stress in different foot types
}

Rajshree Mootanah ${ }^{1,4^{*}}$, Khadija Saoudi ${ }^{2}$, Joel Mazella ${ }^{3}$, Antoine Truchetet ${ }^{2}$, Jonathan Deland ${ }^{4}$, Scott Ellis ${ }^{4}$, Josh Baxter ${ }^{4}$, Howard J Hillstrom ${ }^{4,1}$

From 4th Congress of the International Foot and Ankle Biomechanics (i-FAB) Community

Busan, Korea. 8-11 April 2014

Osteoarthritis (OA) is the leading cause of disability in older adults [1] and $1^{\text {st }}$ metatarsophalangeal joint (MTPJ) OA, is the most common form of OA in the foot [2]. Many foot pathologies are of a biomechanical nature and often associated with one foot type over another [3,4]. OA is postulated to result from elevated joint stress. However, the link between stress distribution in the $1^{\text {st }}$ MTPJ and different foot types is not well understood. Furthermore the tension band effect of the plantar fascia upon $1^{\text {st }}$ MTP joint function is also not well understood.

A high resolution 7 Tesla MRI was used to create a geometrically accurate $3 \mathrm{D}$ model of the $1^{\text {st }}$ MTPJ using Mimics v14 imaging software. To simulate rectus, planus and cavus feet, $1^{\text {st }}$ metatarsal declination angles of $20.2^{\circ}$, $10.1^{\circ}$ and $30.7^{\circ}$ were constructed. Plantar fascia material properties were altered. Physiological material properties and boundary conditions were applied to solve for stress, using ABAQUS. The ligaments were simulated by linear spring elements. The base of the first metatarsal bone was mechanically grounded in this model. Plantar loading conditions were applied, based on plantar pressure data collected from different foot types.

Results of our static 3D FE model (Figure 1) during midstance of gait showed peak stresses in the distal 1st MTPJ cartilage of $0.61 \mathrm{MPa}, 0.97 \mathrm{MPa}$ and $1.10 \mathrm{MPa}$ for the rectus, cavus and planus foot type, respectively (Figure 1). First MTP joint stress is largest for planus and cavus foot
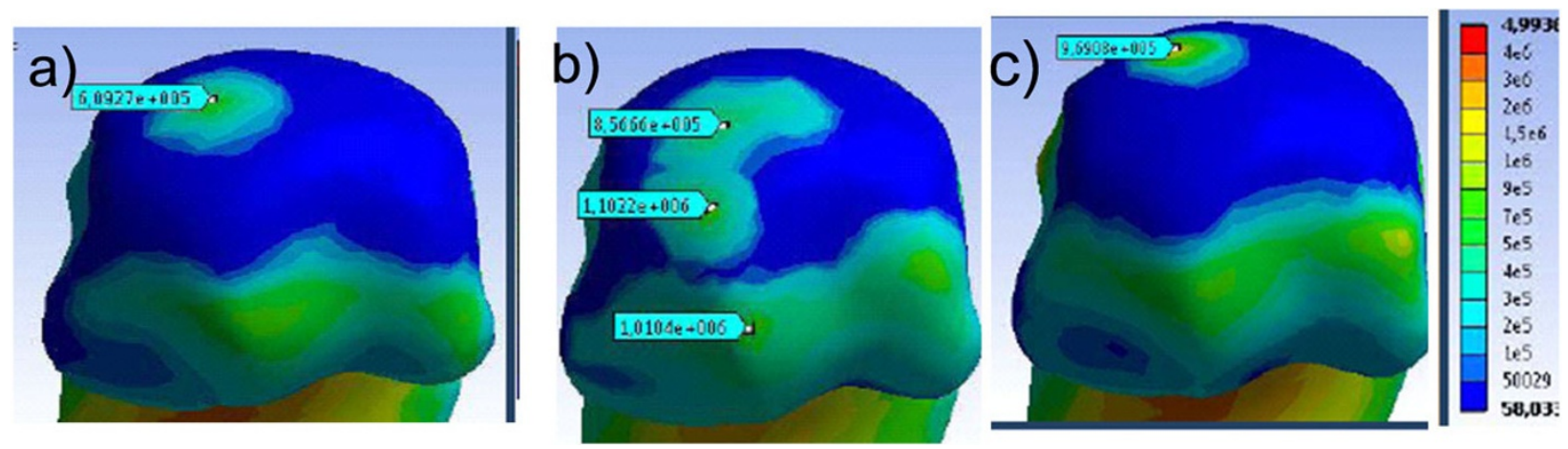

Figure $11^{\text {st }}$ MTPJ stress a) rectus, b) planus, and c) cavus foot types

* Correspondence: rajshree.mootanah@anglia.ac.uk

'Anglia Ruskin University, Chelmsford, Essex, UK

Full list of author information is available at the end of the article 


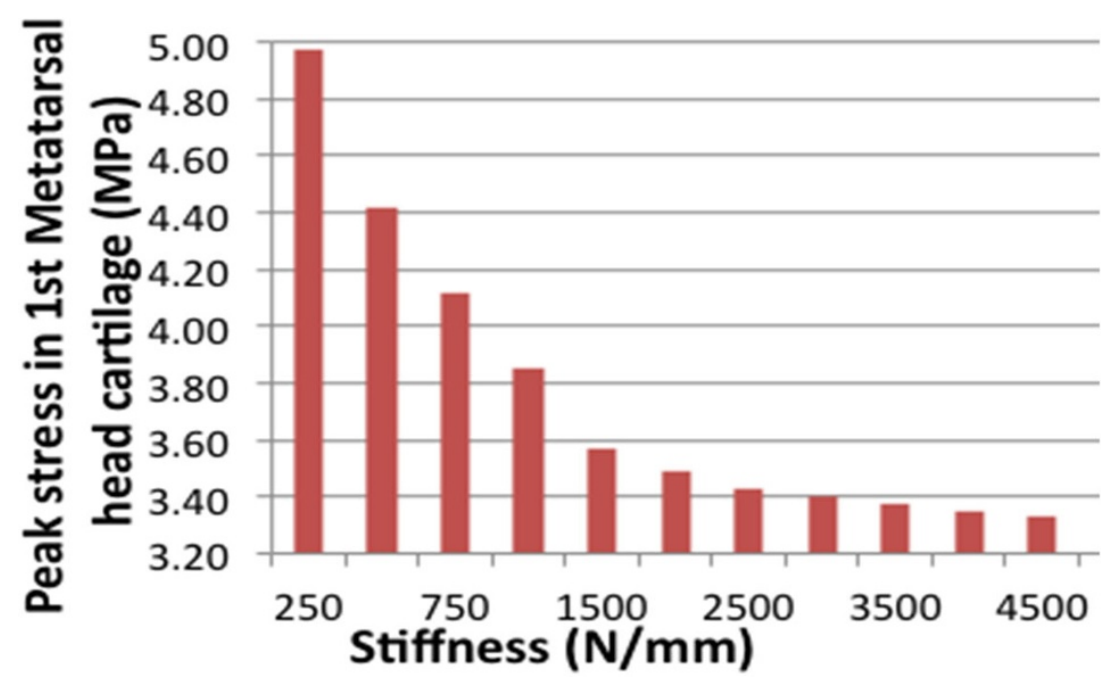

Figure 2 Fascia stiffness effects

types and least for well-aligned rectus feet. Global foot alignment affected the magnitude and location of peak stress within the joint. Peak stress decreases as the $\mathrm{k}$ increases suggesting that the plantar fascia plays an important 'tension band' effect (Figure 2). Future research should develop methods of tuning plantar fascia material properties to represent a specific patient.

\section{Acknowledgement}

This work was in part supported by an NIH grant 1R03HD053135-01.

\section{Authors' details}

${ }^{1}$ Anglia Ruskin University, Chelmsford, Essex, UK. ${ }^{2}$ Universite de Lorraine,

Nancy, France. ${ }^{3}$ Ecole des mines d'Albi-Carmaux, Albi, France. ${ }^{4}$ Hospital for

Special Surgery, NY, USA.

Published: 8 April 2014

\section{References}

1. CDC: MMWR Morb Mortal Wkly Rep 2007, 56(01):4-7.

2. Horton GA, et al: Foot Ankle Int 1999, 20(12):777-80.

3. Ledoux WR, et al: Foot Ankle Int 2003, 24(11):845-850.

4. Sugathan HK, Sherlock DA: J Foot Ankle Surg 2009, 48(6):637-641.

5. Cheung JT, Zhang M, An KN: In Clin Biomech. Volume 19. Bristol, Avon; 2004:(8):839-46.

6. Rao S, Song J, Kraszewski A, et al: Gait Posture 2011, 34(1):131-7.

doi:10.1186/1757-1146-7-S1-A58

Cite this article as: Mootanah et al:: Effects of plantar fascia on first metatarsophalangeal joint stress in different foot types. Journal of Foot and Ankle Research 2014 7(Suppl 1):A58.
Submit your next manuscript to BioMed Central and take full advantage of:

- Convenient online submission

- Thorough peer review

- No space constraints or color figure charges

- Immediate publication on acceptance

- Inclusion in PubMed, CAS, Scopus and Google Scholar

- Research which is freely available for redistribution 